\title{
Antibacterial susceptibility patterns of Porphyromonas gingivalis isolated from chronic periodontitis patients
}

\author{
Aziz Japoni ${ }^{1}$, Afsaneh Vazin ${ }^{2}$, Sadighah Noushadi ${ }^{2}$, Farin kiany ${ }^{3}$, Sara Japoni ${ }^{1}$, Abdolvahab Alborzi ${ }^{1}$ \\ ${ }^{1}$ Professor Alborzi Clinical Microbiology Research Center, Nemazee hospital, Shiraz pharmaceutical research center, Shiraz \\ University of medical Sciences, Shiraz, Iran \\ ${ }^{2}$ Shiraz pharmaceutical research center, Shiraz University of medical Sciences, Shiraz, Iran \\ ${ }^{3}$ Department of periodontology, School of Dentistry, Shiraz University of Medical Sciences, Shiraz, Iran
}

Correspondence:

Clinical Microbiology Research Center,

Nemazee hospital,

Shiraz University of Medical Sciences,

71037-11351, Shiraz, Iran

Japonia@hotmail.com

Received: 28/06/2010

Accepted: $14 / 11 / 2010$

\begin{abstract}
Japoni A, Vasin A, Noushadi S, Kiany F, Japoni S, Alborzi A. Antibacterial susceptibility patterns of Porphyromonas gingivalis isolated from chronic periodontitis patients. Med Oral Patol Oral Cir Bucal. 2011 Nov 1;16 (7):e1031-5.

http://www.medicinaoral.com/medoralfree01/v16i7/medoralv16i7p1031.pdf
\end{abstract}

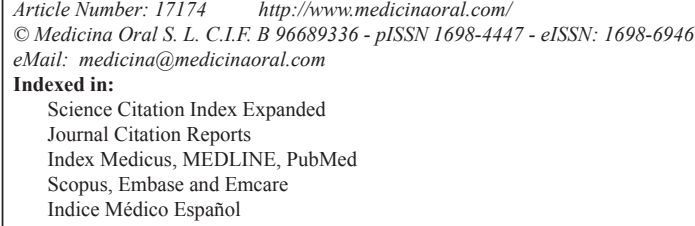

\begin{abstract}
Objectives: To test the antimicrobial sensitivity of Porphyromonas gingivalis to a panel of eight orally administrable antibiotics in chronic periodontal diseases and to evaluate factors associated with periodontitis in adult patients.

Study Design: A total of fifty strains of P. gingivalis were isolated from one hundred and twenty adult patients with chronic perio-dontitis. Identification of bacteria was carried out by anaerobic culture and biochemical tests. Selected colonies of P. gingivalis were used to evaluate the antibacterial activities of penicillin, metronidazole, amoxicillin, amoxicillin/clavulanic acid, clindamycin, doxy-cycline, ciprofloxacin and azithromycin.

Results: Most of the patients were female, age ranging between 40 to 50 years. Majority of the patients frequently had scaling and depths of periodontal pockets in infected teeth were 5-8 $\mathrm{mm}$ and most of them had hemorrhage during sampling. Susceptibility testing revealed a sensitivity of $100 \%$ of P. gingivalis to azithromycin, doxycycline and amoxicillin/clavulanic acid but lower susceptibilities were found for the rest of antibiotic agents evaluated. Conclusions: Frequent scaling in women aged between 40-50 years had positive correlation with chronic periodontitis. The application of antibiotics in conjuction with mechanical debridation, may reflect in the level of resistance of $\mathrm{P}$. gingivalis in patients with chronic periodontal infections. This could suggest periodical antibiotic susceptibility testing is necessary to determine the efficacy of antimicrobial agents if the perfect curing of chronic periodontal diseases after mechanical debridation is meant. Further clinical studies are required to confirm the in vitro results. The only limitation in this study was identification of bacteria to species rather than subspecies level.
\end{abstract}

Key words: Scaling, antibiotics, chronic periodontal diseases, resistance. 


\section{Introduction}

Porphyromonas gingivalis belongs to the genus Bacteroides and is a non-motile, gram-negative, rod-shaped, anaerobic pathogenic bacterium. It forms black colonies on blood agar. P. gingivalis is pathogenic bacterium, commonly found in the human body and especially in the oral cavity, associated with periodontal lesions, infections, and adult periodontal diseases (1).

The American Academy of Periodontology classification system was established to identify the distinct types of periodontal diseases by taking into consideration factors such as age of onset, clinical appearance, and rate of disease progression, pathogenic microbial flora and systemic influences (2). Periodontitis, a bacterially induced, localized, chronic inflammatory disease, destroys connective tissues and bones that support the teeth. It is common, with mild to moderate forms affecting $30 \%$ to $50 \%$ of the adults and the severe, chronic forms affecting $5 \%$ to $15 \%$ of all adults in the United States (3). Periodontitis has even higher prevalence in developing countries and considerable global variation, although the prevalence of the severe generalized disease appears to be similar in most populations (4).

Drug resistance of $\mathrm{P}$. gingivalis in periodontal diseases is implicated in the pathogenesis of periodontitis $(5,6)$. These bacteria are able to produce virulence factors that act locally within the sulcus, and result in tissue destruction $(5,6)$. Among them, cell-surface-associated and secreted proteinases such as Arg-gingipain and Lys-gingipain and proteolytic enzymes have received much attention because they can degrade various host proteins and cause inflammation (6). P. gingivalis has shown the ability to invade human gingival fibroblasts and oral epithelial cells in cell culture (7). It has been reported that from 13 isolates recovered from protected bronchoalveolar lavage fluid, nine respiratory pathogens matched genetically those recovered from the corresponding dental plaque of eight patients (8). Based on the recent reports, systemic antibiotics should not be used in most adult patients with periodontitis. Therefore, their application should be restricted to specific conditions such as aggressive or severe progressive periodontitis (9). Clindamycin, metronidazole and amoxicillin are the antibiotics commonly used in conjunction with mechanical debridation (10-12). Besides, positive responses have been reported with amoxicillin/clavulanic acid in the treatment of periodontitis $(10,12)$.

The present study aimed to test, in vitro, the susceptibility of P. gingivalis, isolated from periodontal pockets in adult patients with chronic periodontitis, to eight orally administrable antibiotics and to investigate the factors associated with chronic periodontal disease trigger.

\section{Materials and Methods}

Selection of patients

Inclusion criteria

One hundred twenty adults with chronic periodontal disease, attending the clinic of dentistry, division of periodontology, Shiraz, Iran, from june 2008 to march 2009 were enrolled in the study. Written informed consents were obtained from all the patients, and approved by the ethics board of Shiraz University of Medical Sciences. Patients with generalized to severe, chronic periodontitis with more than $3 \mathrm{~mm}$ attachment loss in more than $30 \%$ of teeth and with $4-7 \mathrm{~mm}$ true periodontal pockets, were included in the study (13).

\section{Exclusion criteria}

Patients with the following conditions were excluded from the study: pregnancy, systemic diseases that influence periodontium or interfere with examination or sampling, smoking, consuming antibiotics during last three months, corticosteroid consumption and history of periodontal disease during last six months.

\section{Sampling}

One hundred and twenty patients with the above-mentioned characteristics were selected. One tooth from each patient was selected (120 teeth), after isolation of the tooth with cotton roll, supragingival was removed with curette and gingival crevicular fluid was collected by insertion of two paper points into pocket for 30 seconds. Paper points were then transferred quickly into $2 \mathrm{ml}$ transport media (brucella broth; BBL Microbiology Systems, Cockeysville, Md. supplemented with $0.4-\mu 1 / \mathrm{ml}$ vitamin $\mathrm{K} 1$ and $5-\mu \mathrm{g} / \mathrm{ml}$ hemin; Sigma Chemical Co.).

\section{Isolation of P.gingivalis}

Brucella broth containing patients' samples were then diluted and plated out onto trypticase soy agar (BBL Microbiology Systems), supplemented with 10\% defibrinated horse blood, $5-\mu \mathrm{g} / \mathrm{ml}$ hemin, and $0.4-\mu \mathrm{l} / \mathrm{ml}$ vitamin $\mathrm{K} 1$. The plates were incubated in duplicate in an anaerobic atmosphere containing $80 \% \mathrm{~N}_{2}, 10 \% \mathrm{CO}_{2}$ and $10 \% \mathrm{H}_{2}$ for 7 to 10 days. The bacteria were selected on the basis of size, color, shape, staining and biochemical tests. Those with black-pigmented colonies, gram-negative rods were submitted to a fluorescence test by long wave UV light. Absence of fluorescence was considered as a rapid taxonomic test to distinguish between $\mathrm{P}$. gingivalis and other black-pigmented, anaerobic, gram-negative rods (14). Isolates were then identified as P. gingivalis based on catalase and indole tests, glucose fermentation and sheep red blood cell agglutination. In each of the anaerobic culture batch, standard type strain (American Typing Collection; ATCC 33277) was also included to facilitate the comparison of bacterial colonies, morphology, and results of biochemical tests of the isolated bacteria with the standard type.

\section{Antibacterial susceptibility patterns}

The minimal inhibitory concentrations (MICs) of fifty isolates of P. gingivalis to eight antibiotics including, metronidazole, penicillin, clindamycin, ciprofloxacin, doxycycline, amoxicillin, amoxicillin/clavulanic acid and azithromycin were determined by the $\mathrm{E}$ test method (AB Biodisk, Sweden). American Typing Collection (ATCC 
33277) of $\mathrm{P}$. gingivalis was used as a control strain in antibacterial susceptibility testing. Bacterial strains were grown on blood agar plates (Oxoid no. 2, Basingstoke, UK), supplemented with 5\% sheep blood, hemin (5 mg/l) and $0.4-\mu \mathrm{l} / \mathrm{ml}$ vitamin $\mathrm{K} 1$ for 5 days. Then, test organisms were suspended in sterile phosphate-buffered saline equivalent to a $0.5 \mathrm{McFarland}$ standard and streaked confluently over the surface blood agar plates. Plates were incubated in $80 \% \mathrm{~N}_{2}, 10 \% \mathrm{CO}_{2}$ and $10 \% \mathrm{H}_{2}$ for 3 to 5 days. Inhibition zones were measured according to the recommendations of the manufacturer.

\section{Results}

Of one hundred twenty patients enrolled in the study, P. gingivalis solated from $50(41.7 \%)$ of the them. Most pa- tients were female (62\% versus 38\%) and the age range of 40 to 50 years was predominant (54\%), compared lower or upper age ranges, $(24 \%$ or $22 \%$, respectively) (Table 1). As for the educational status of the patients, the majority of them were undergraduate. As revealed, most of them had daily brushing (72\%) and never used dental floss $(96 \%)$ and they had several times scaling (72\%). In $62 \%$ of the patients, depths of periodontal pocket were 5-8 $\mathrm{mm}$ and majority of them (96\%) had hemorrhage during sampling (Table 1). Based on antibacterial susceptibility determination, three antibiotics had perfect (100\%) activities against $\mathrm{P}$. gingivalis while the rest showed 60 to $96 \%$ efficacy against the isolates (Table 2). $\mathrm{MIC}_{50}$ and $\mathrm{MIC}_{90}$ of the three most effective antibiotics were lower, compared with the rest of

Table 1. Demographic information and factors associated with chronic periodontitis in 50 adult patients.

\begin{tabular}{|c|c|c|c|}
\hline \multicolumn{2}{|c|}{$\begin{array}{c}\text { Demographic data and factors associated } \\
\text { with periodontitis }\end{array}$} & Number & Percentage \\
\hline \multirow{2}{*}{ Gender } & Male & 19 & 38 \\
& Female & 31 & 62 \\
\hline \multirow{2}{*}{ Age } & $30-40$ & 12 & 24 \\
& $40-50$ & 27 & 54 \\
Education & $>50$ & 11 & 22 \\
\hline \multirow{2}{*}{ Brushing } & Under graduate & 31 & 62 \\
& Graduate & 19 & 38 \\
\hline \multirow{2}{*}{ Use of dental floss } & Seldom & 7 & 14 \\
& Several times a week & 7 & 14 \\
& Daily & 36 & 72 \\
\hline \multirow{2}{*}{ Scaling } & Daily & 2 & 4 \\
& Never & 48 & 96 \\
\hline \multirow{2}{*}{ Depth of periodontal pocket } & Several times & 36 & 72 \\
& Never & 14 & 28 \\
\hline \multirow{2}{*}{ Hemorrhage when sampling } & $5-8$ mm & 31 & 62 \\
& $>8$ mm & 19 & 38 \\
\hline
\end{tabular}

Table 2. Minimum inhibitory concentration (MIC) of fifty strains of P. gingivalis isolated from the patients with chronic periodontal diseases.

\begin{tabular}{|l|c|c|c|c|c|c|}
\hline \multicolumn{1}{|c|}{ Antibiotic } & MIC range( $\mathbf{\mu g} / \mathbf{m l})$ & $\begin{array}{c}\mathbf{M I C}_{\mathbf{5 0}}{ }^{\mathbf{a}} \\
(\boldsymbol{\mu g} / \mathbf{m l})\end{array}$ & $\begin{array}{c}\mathbf{M I C}_{\mathbf{9}} \mathbf{a} \\
(\boldsymbol{\mu g} / \mathbf{m l})\end{array}$ & $\begin{array}{c}\text { Sensitive } \\
\mathbf{n}(\mathbf{\%})\end{array}$ & $\begin{array}{c}\text { Intermediate } \\
\text { resistant n (\%) }\end{array}$ & $\begin{array}{c}\text { Resistant } \\
\mathbf{n}(\mathbf{\%})\end{array}$ \\
\hline Metronidazole & $0.016-\geq 1$ & 0.016 & 0.5 & $47(94)$ & 0 & $3(6)$ \\
\hline Penicillin & $0.002-1$ & 0.023 & 0.5 & $46(92)$ & $1(2)$ & $3(6)$ \\
\hline Co-Amoxiclav & $0.016-0.125$ & 0.016 & 0.125 & $50(100)$ & 0 & 0 \\
\hline Clindomycin & $0.016-0.08$ & 0.016 & 0.047 & $48(96)$ & 0 & $2(4)$ \\
\hline Doxycycline & $0.016-0.5$ & 0.032 & 0.5 & $50(100)$ & 0 & 0 \\
\hline Amoxicillin & $0.016-2$ & 0.024 & 1 & $44(88)$ & $2(4)$ & $4(8)$ \\
\hline Ciprofloxacin & $0.002-1$ & 0.094 & 0.75 & $30(60)$ & $16(32)$ & $4(8)$ \\
\hline Azithromycin & $0.002-0.38$ & 0.032 & 0.38 & $50(100)$ & 0 & 0 \\
\hline
\end{tabular}

a MIC50 and MIC90 indicate the MIC values at which 50\% and 90\% of the tested isolates were inhibited, respectively. 
Table 3. Cross-resistance of fifty isolates of P.gingivalis to the tested antibiotics.

\begin{tabular}{|c|c|c|c|c|c|c|}
\hline \multicolumn{7}{|c|}{$\begin{array}{c}\text { Number of isolates and percent } \\
\text { (value in parenthesis) resistant to }\end{array}$} \\
\hline \multicolumn{2}{|c|}{ Number } & MET & PEN & CLN & AMC & CIP \\
\hline MET & 3 & & 0 & $1(33.3)$ & $1(33.3)$ & $1(33.3)$ \\
\hline PEN & 3 & 0 & & $1(33.3)$ & $1(33.3)$ & $1(33.3)$ \\
\hline CLN & 2 & $1(50)$ & $1(50)$ & & 0 & $2(100)$ \\
\hline AMC & 4 & $1(25)$ & $1(25)$ & 0 & & $2(100)$ \\
\hline CIP & 4 & $1(25)$ & $1(25)$ & $2(50)$ & 0 & \\
\hline
\end{tabular}

Abbreviations: MET; metronidazole, PEN; penicillin, CLN; clindamycin, AMC; amoxicillin, CIP; ciprofloxacin.

the antibiotics. Antibiotic resistant isolates expressed cross-resistance to the other tested antibiotics, ranging between 33 . $3 \%$ to $100 \%$ (Table 3).

\section{Discussion}

P. gingivalis is considered as a major etiological agent in the onset and progression of chronic destructive periodontitis. In the present study, associations between several factors with chronic periodontitis have been observed. Majority of the patients were women (62\%) aging between 40-50 years old. The greater incidence of periodontitis among the females may be due to inappropriate attention to the oral hygiene. Hormonal production and experiences of the pregnancies in females within the age range of 40-50 years could cause reduction in the composition of body minerals including bone and teeth $(15,16)$, which may predispose them to more periodontal diseases (17). It has also been proposed that high education could reflect in quality of life, so that the undergraduate patients in this study may not have had enough attention to their oral hygiene (18). Majority of the patients in this investigation had daily brushing but as dentists' reports inadequate or wrong brushing is also evident. This might be the reason why periodontal disease was even more common among those with regular brushing (19). In this study the majority (72\%) of the patients previously had several times scaling. The need for scaling may also be associated with poor oral hygiene and smoking $(20,21)$. Therefore, it could be direct association between periodontal diseases and dental caries with scaling specially when carried out frequently in short period of time. It has been suggested that depths of periodontal pocket in the patients with aggressive infections are deeper when compared with patients with moderate periodontitis (22), as also seen in the present study. Nevertheless, in addition to the factors mentioned above, other factors such as smoking and special food habits may be associated with periodontal disease and should be taken into account $(23,24)$.

The results of the present study showed that three antibiotics including amoxicillin/clavulanic acid, doxycycline and azithromycin had 100\% activities against $\mathrm{P}$. gingivalis which can provide alternative antibiotics to treat the patients whenever indicated. The fact that $12 \%$ of the bacteria were resistant or intermediate resistant to amoxicillin but $100 \%$ were sensitive to amoxicillin/clavulanic acid, indicates that resistance of $\mathrm{P}$. gingivalis to $\beta$-lactam antibiotics are due to $\beta$-lactamase production $(25,26)$. Low values of $\mathrm{MIC}_{50}$ and $\mathrm{MIC}_{90}$ of the three effective antibiotics were also noticed in this study, which could suggest that systemic antibiotic therapy may deliver adequate drug inside the infected teeth $(27,28)$. However, this speculation needs to be confirmed with clinical trials. Availability of alternative effective antibiotics could help the clinicians appropriately prescribe them based on the patients' individual conditions. Resistance to the five antibiotics, as observed in our study, implies the rational use of effective antibiotics to prevent the increasing resistance rate and to preserve the efficacy of the antibiotics. In agreement with the present study, temporal and geographic changes in antibiotic susceptibility among anaerobes have been reported in Europe and Latin America $(29,30)$. The only limitation in this study was identification of bacteria to species rather than subspecies level. Further studies into the identification of bacteria at subspecies level, using API 20A method are recommended.

In summary, the present study reveals a positive correlation of gender, age and scaling with chronic periodontitis in adults. Three antibiotics including azithromycin, doxycycline and amoxicillin/clavulanic acid were found to be $100 \%$ active against $\mathrm{P}$. gingivalis in vitro, however, this finding needs to be confirmed with further clinical trials. 


\section{References with links to Crossref - DOI}

\section{References}

1. Socransky SS, Smith C, Haffajee AD. Subgingival microbial profiles in refractory periodontal disease. J Clin Periodontol. 2002;29:260-8.

2. Friedewald VE, Kornman KS, Beck JD, Genco R, Goldfine A, Libby P et al. The American Journal of Cardiology and Journal of Periodontology editors' consensus: periodontitis and atherosclerotic cardiovascular disease. J Periodontol. 2009;80:1021-32.

3. Burt B, Research, Science and Therapy Committee of the American Academy of Periodontology. Position paper: epidemiology of periodontal diseases. J Periodontol. 2005;76:1406-19.

4. Pihlstrom BL, Michalowicz BS, Johnson NW. Periodontal diseases. Lancet. 2005;366:1809-20.

5. Tribble GD, Lamont GJ, Progulske-Fox A, Lamont RJ. Conjugal transfer of chromosomal DNA contributes to genetic variation in the oral pathogen Porphyromonas gingivalis. J Bacteriol. 2007;189:6382-8.

6. Fives-Taylor PM, Meyer DH, Mintz KP, Brissette C. Virulence factors of Actinobacillus actinomycetemcomitans. Periodontol 2000. 1999;20:136-67.

7. Rudney JD, Chen R, Sedgewick GJ. Intracellular Actinobacillus actinomycetemcomitans and Porphyromonas gingivalis in buccal epithelial cells collected from human subjects. Infect Immun. 2001;69:2700-7.

8. El-Solh AA, Pietrantoni C, Bhat A, Okada M, Zambon J, Aquilina A, et al. Colonization of dental plaques: a reservoir of respiratory pathogens for hospital-acquired pneumonia in institutionalized elders. Chest. 2004;126:1575-82.

9. Herrera D, Alonso B, León R, Roldán S, Sanz M. Antimicrobial therapy in periodontitis: the use of systemic antimicrobials against the subgingival biofilm. J Clin Periodontol. 2008;35:45-66.

10. Walker C, Karpinia K. Rationale for use of antibiotics in periodontics. J Periodontol. 2002;73:1188-96.

11. Guentsch A, Jentsch H, Pfister W, Hoffmann T, Eick S. Moxifloxacin as an adjunctive antibiotic in the treatment of severe chronic periodontitis. J Periodontol. 2008;79:1894-903.

12. Van Winkelhoff AJ, Herrera D, Oteo A, Sanz M. Antimicrobial profiles of periodontal pathogens isolated from periodontitis patients in The Netherlands and Spain. J Clin Periodontol. 2005;32:893-8.

13. Ardila CM, López MA, Guzmán IC. High resistance against clindamycin, metronidazole and amoxicillin in Porphyromonas gingivalis and Aggregatibacter actinomycetemcomitans isolates of periodontal disease. Med Oral Patol Oral Cir Bucal. 2010;15:e947-51.

14. Slots J, Reynolds HS. Long-wave UV light fluorescence for identification of black-pigmented Bacteroides spp. J Clin Microbiol. 1982;16:1148-51.

15. Den Hartog AG, Algra A, Moll FL, de Borst GJ. Mechanisms of gender-related outcome differences after carotid endarterectomy. J Vasc Surg. 2010;52:1062-71, 1071.e1-6.

16. Namgung R, Tsang RC. Bone in the pregnant mother and newborn at birth. Clin Chim Acta. 2003;333:1-11.

17. Huebner CE, Milgrom P, Conrad D, Lee RS. Providing dental care to pregnant patients: a survey of Oregon general dentists. J Am Dent Assoc. 2009;140:211-22.

18. Polk DE, Weyant RJ, Manz MC. Socioeconomic factors in adolescents' oral health: are they mediated by oral hygiene behaviors or preventive interventions? Community Dent Oral Epidemiol. 2010;38:1-9.

19. Carlos MC, Muyco MM, Caliwag MC, Fajardo JA, Uy HG. The prevalence and distribution of gingival recession among U.E. dental students with a high standard of oral hygiene. J Philipp Dent Assoc. 1995;47:27-48.

20. Wang Z, Zhou X, Zhang J, Zhang L, Song Y, Hu FB, et al. Periodontal health, oral health behaviours, and chronic obstructive pulmonary disease. J Clin Periodontol. 2009;36:750-5.

21. Dalia D, Palmer RM, Wilson RF. Management of smoking patients by specialist periodontists and hygienists in the United Kingdom. J Clin Periodontol. 2007;34:416-22.
22. Savage A, Eaton KA, Moles DR, Needleman I. A systematic review of definitions of periodontitis and methods that have been used to identify this disease. J Clin Periodontol. 2009;36:458-67.

23. Daly RM, Elsner RJ, Allen PF, Burke FM. Associations between self-reported dental status and diet. J Oral Rehabil. 2003;30:964-70. 24. Hashim R, Williams SM, Murray Thomson W. Diet and caries experience among preschool children in Ajman, United Arab Emirates. Eur J Oral Sci. 2009;117:734-40.

25. Blandino G, Milazzo I, Fazio D, Puglisi S, Pisano M, Speciale A, et al. Antimicrobial susceptibility and beta-lactamase production of anaerobic and aerobic bacteria isolated from pus specimens from orofacial infections. J Chemother. 2007;19:495-9.

26. Bahar H, Torun MM, Demirci M, Kocazeybek B. Antimicrobial resistance and beta-lactamase production of clinical isolates of prevotella and porphyromonas species. Chemotherapy. 2005;51:9-14.

27. Feres M, Haffajee AD, Goncalves C, Allard KA, Som S, Smith C, et al. Systemic doxycycline administration in the treatment of periodontal infections (I). Effect on the subgingival microbiota. J Clin Periodontol. 1999;26:775-83.

28. Hanes PJ, Purvis JP. Local anti-infective therapy: pharmacological agents. A systematic review. Ann Periodontol. 2003;8:79-98.

29. Herrera D, Contreras A, Gamonal J, Oteo A, Jaramillo A, Silva N, et al. Subgingival microbial profiles in chronic periodontitis patients from Chile, Colombia and Spain. J Clin Periodontol. 2008;35:10613.

30. Valenzuela MT, de Quadros C. Antibiotic resistance in Latin America: a cause for alarm. Vaccine. 2009;27 Suppl 3:C25-8.

\section{Conflict of Interest and Source of Funding Statement}

This study was supported by the grant No. 87-15, Shiraz University of Medical Sciences. The authors declare that there is no conflict of interest to be stated.

\section{Acknowledgment}

Our thanks go to Hassan Khajehei for his linguistic copy editing. 